\title{
Review on the Effects of Increased Social Media Use on Depressive Symptoms in Adolescents
}

\section{AQSA ZAHID}

Department of Psychology, University of Toronto Scarborough, Canada

\section{Abstract}

Social media (SM) allow individuals to connect with one another through online networking and serves various purposes (e.g., knowledge accumulation, communication, etc.). However, increased use of SM can have detrimental effects among the adolescent population, specifically in terms of their mental health. The present review examines the influence of increased SM use on the rates of depressive symptoms (DS) found in adolescents. Approximately 40 articles were initially reviewed to examine whether they met the inclusion criteria (primary research article published after 2015 that examines DS in adolescents who use SM). Based on these criteria, seven articles were located and reviewed. Overall, they generally found that an increase in SM use is associated with an increase in rates of DS in adolescents. This finding is crucial as it evidences a potentially strong correlation between SM use and DS in a large percentage of adolescents globally. Hence, psychological professionals (e.g., therapists, psychologists, clinical psychologists, psychiatrists) should consider looking into their clients' SM use prior to applying therapeutic interventions.

Keywords: social media, adolescents, depressive symptoms

\section{Introduction}

Social media (SM) are interactive websites or applications that allow users to connect with others and create online networks (Obar \& Wildman, 2015). Although there are benefits of SM use in adolescence (e.g., strengthening current friendships and forming new friendships; O'Keeffe et al., 2011), there are also many disadvantages such as experiencing higher rates of depressive symptoms (DS) and anxiety (Lemola et al., 2015). As $92 \%$ of adolescents between the ages of 13 and 17 use SM every day, it is bound to have widespread impacts-both positive and negative-on adolescents (Lenhart, 2015).

Adolescence is a critical time period when significant development occurs. For example, as described by Blos (1967), adolescence is a period of second individuation. More specifically, this is a period during which individuals develop 
new relationships, and a sense of selfidentity. With increased social media use, adolescents gain more experience in communicating with others and improve their emotional intelligence. Despite having greater emotional intelligence (Goleman, 2009), adolescents begin to struggle in utilizing verbal and intellectual skills and communicating their emotions. The use of SM (e.g., online chatting) may allow adolescents to interact with peers in more emotionally meaningful ways than do face-to-face interactions (Koutamanis et al., 2013). However, studies have also shown that SM use, such as through Facebook, can reinforce feelings of loneliness among adolescents (Kross et al., 2013).

Thus, SM may potentially lead to an increase in the prevalence of DS in adolescents. Existing empirical evidence suggests a positive association between increased SM use and DS among adolescents, such that individuals who utilize SM more also report higher levels of DS (Nesi \& Prinstein, 2018). It is important to note that there is also evidence suggesting that the association between SM use and DS among adolescents is weak (Muzaffar et al., 2018). Due to the controversial results found in the literature, it has not been well established whether or not there exists a harmful effect of SM use on the progression of DS in adolescents.

The implications of such findings are important as psychotherapists and clinical psychologists may want to incorporate SM use as a key measure when assessing adolescent depression and selecting effective treatments. Interpersonal Psychotherapy (IPT) is an evidence-based psychotherapy for depression that focuses on resolving interpersonal problems. The significance of IPT has recently been underscored in the context of SM use, as this therapeutic framework can be used to further analyze the impact of technology on the strength and health of interpersonal relationships (Swartz \& Novick, 2020). Therapists may utilize IPT to inform issues relating to SM use and interpersonal relationships in individuals diagnosed with depression. Understanding the relationship between SM use and mental health would allow therapists to ascertain a link between the two and address related behaviours (i.e., time spent on SM) during therapy sessions.

The purpose of the current literature review is to determine if adolescents who use SM experience higher rates of DS compared to individuals who do not use SM. Based on what has been stated in the popular press and what is known on adolescent development, I hypothesized that an increased use of SM by adolescents will predict higher rates of DS.

\section{Methods}

Throughout the review process, 47 articles were reviewed. To ensure that each study 
met the inclusion criteria, the key words and abstracts of each experimental study were reviewed. Many studies were not included in this review due to publication year and sample characteristics criteria. In terms of sample demography, this literature review focused on young adolescents due to the fact that individuals in this age population are going through many developmental changes, forming a self-identity, and overall are vulnerable to the effects of SM use. since SM is used by individuals all over the world, there were no limitations in terms of the country in which the studies were conducted. These criteria were fitting with the primary evidence base, which was defined as primary research articles published after 2015 that examine DS in adolescents who use SM.

PsyclNFO Thesaurus was used to retrieve all articles for the present literature review. Our initial search began with the input of three key search terms: "mental health," "social media," and "adolescents." From this, the search was refined so that all articles listed were published on or after 2015. The search was then further refined to peer-reviewed experimental studies. Based on these criteria, studies conducted by Dhir et al. (2018), Woods and Scott (2016), and Vannucci and Ohannessian (2019) were located. After reviewing the abstract and methodology of these articles, the search term was then further refined to include "depression" as a key word. This key word was added because DS is the dependant variable being studied in this review. Hence, the studies included should be examining levels of DS expressed by adolescents. Based on the addition of this key word, studies conducted by Frison and Eggermont (2015) and Nesi and Prinstein (2018) were retrieved. To limit our investigation based on the SM platform (e.g., Facebook, Instagram, Twitter), the key word "Facebook" was added, as this will be the operational definition of "social media" in this literature review. Relative to other forms of SM, Facebook is older and has a larger body of users (Lenhart, 2015). Thus, it is expected that more studies have been conducted with this SM platform. After this search refinement, studies by Muzaffar et al. (2018) and Ophir et al. (2019) were located.

For this review, the commonality of Facebook as an independent variable was included by way of the primary evidence base. However, other forms of SM such as Instagram (Nesi \& Prinstein, 2018; Vannucci \& Ohannessian, 2019) and Snapchat (Vannucci \& Ohannessian, 2019) are often included as independent variables as well. This review solely focussed on Facebook use among adolescents. Also, the dependent variable is also operationalized in different alignments with each study's purpose. All studies included in the primary evidence base have included rates of DS in the dependant variable. Studies included in 
this review also analyzed other variables such as rates of anxiety (Dhir et al., 2018; Muzaffar et al., 2018; Woods \& Scott, 2016), social rejection and bullying victimization (Ophir et al., 2019), online social support (Frison \& Eggermont, 2015), social comparison and feedback seeking (Nesi \& Prinstein, 2018), and social functioning (Vannucci \& Ohannessian, 2019). All of these variables are often additionally constituting the dependant variable to measure psychological and social functioning as a whole.

\section{Results}

A total of seven peer-reviewed experimental studies published on or after 2015 examining rates of DS in adolescents using SM were included in the primary evidence base (see Table 1). Six studies in the primary evidence base used self-report measures (SRMs) to assess the rates of DS in adolescents. All studies used Facebook use as the operational definition for SM.

The overall pattern of findings is that an increase in SM use is associated with an increase in rates of DS (Dhir et al., 2018; Nesi \& Prinstein, 2018; Vannucci \& Ohannessian, 2019; Woods \& Scott, 2016). Two studies (Frison \& Eggermont, 2015; Ophir et al., 2019) found partial support for the positive association between SM use and DS, as this link was only supported under certain conditions. Specifically, support for the hypothesis was found in females who passively used SM, males who actively used SM (Frison \&
Eggermont, 2015), individuals who explicitly post about their distress, and individuals who indirectly use Facebook (Ophir et al., 2019). The relationship between DS and SM use is somewhat consistent across the studies that have been reviewed. However, a consensus has not been found. Of the seven studies that have been reviewed, one study (Muzaffar et al., 2018) concluded that there is no association between DS and SM use. Instead, this study concluded that there does not exist an association between Facebook behaviour (i.e., number of friends, time spent on Facebook) and social anxiety symptoms, DS, and general distress (Muzaffar et al., 2018).

To understand these results, it is important to consider contextual factors such as the methods used to measure DS. Only one study made use of a model (stressor-strain-outcome model; Dhir et al., 2018). In the other six studies, researchers used SRMs to determine DS rates in adolescents. Although Dhir and colleagues (2018) utilized a different method to measure DS rates, the results obtained are similar to those of three other studies in this review (Nesi \& Prinstein, 2018; Vannucci \& Ohannessian, 2019; Woods \& Scott, 2016), which all found that an increased use of SM predicted DS levels in adolescents. 
Table 1. Summary of seven studies included in final collection for literature review.

\begin{tabular}{|c|c|c|c|}
\hline Article & Methodology & Results & $\begin{array}{c}\text { Support } \\
\text { hypothesis? }\end{array}$ \\
\hline Dhir et al., 2018 & $\begin{array}{l}\text { Stressor-strain-outcome model used. Repeated } \\
\text { cross-sectional method used. Data was collected in } \\
\text { two waves }(\mathrm{N}=1554,1144) \text {. }\end{array}$ & Increase in SM use $\uparrow$ fatigue $\uparrow$ anxiety and DS. & Yes \\
\hline $\begin{array}{l}\text { Frison \& Eggermont, } \\
2015\end{array}$ & $\begin{array}{l}\text { Adolescents }(\mathrm{N}=910) \text { completed a battery of } \\
\text { questionnaires. Questions were related to } \\
\text { active/passive use of Facebook, perceived online } \\
\text { social support and DS. }\end{array}$ & $\begin{array}{c}\text { Females + passive use } \uparrow \text { DS. } \\
\text { Males }+ \text { active public use } \uparrow \text { DS. } \\
\text { Females + active use }+ \text { perceived online social } \\
\text { support } \downarrow \text { DS. }\end{array}$ & Partial \\
\hline Muzaffar et al., 2018 & $\begin{array}{l}\text { Participants }(\mathrm{N}=102) \text { were surveyed about } \\
\text { general/social anxiety and DS. They were also } \\
\text { administered Facebook behaviour measures to } \\
\text { measure Facebook use/activity. }\end{array}$ & $\begin{array}{c}\text { Social anxiety/general distress/DS were not } \\
\text { associated with Facebook behaviour and utilization. } \\
\text { However, general anxiety symptoms were related to } \\
\text { increased Facebook use. }\end{array}$ & No \\
\hline Nesi \& Prinstein, 2018 & $\begin{array}{c}\text { Adolescents }(\mathrm{N}=619) \text { completed a battery of } \\
\text { questionnaires in two cohorts, one year apart. } \\
\text { Participants answered questions related to } \\
\text { reassurance/feedback seeking, DS, and social } \\
\text { comparison. }\end{array}$ & $\begin{array}{l}\text { Social comparison and feedback seeking are } \\
\text { associated with DS. This association was stronger } \\
\text { among females than males. }\end{array}$ & Yes \\
\hline Ophir et al., 2019 & $\begin{array}{l}\text { Two studies were conducted with adolescents }(\mathrm{N}= \\
86,182) \text {. Participants completed SRMs on social } \\
\text { rejection, bullying victimization, and DS. }\end{array}$ & $\begin{array}{l}\text { Study 1: Explicit mention of distress in Facebook } \\
\text { posts are correlated with DS, but such posts are rare. } \\
\text { Study 2: social rejection and bullying victimization } \\
\text { are predicted by indirect Facebook use (others' } \\
\text { posts, dark content, etc.). }\end{array}$ & Partial \\
\hline $\begin{array}{l}\text { Vannucci \& } \\
\text { Ohannessian, } 2019\end{array}$ & $\begin{array}{l}\text { Participants }(\mathrm{N}=1205) \text { completed questionnaires } \\
\text { in two waves, six months apart. Use of SM was } \\
\text { classified into three groups: high overall use, high } \\
\text { Snapchat/Instagram use, low use. }\end{array}$ & $\begin{array}{l}\text { Those who were in "high use" of SM predicted } \\
\text { higher rates of DS and panic disorder symptoms, } \\
\text { family conflict, delinquent behaviour, and lower } \\
\text { social support. }\end{array}$ & Yes \\
\hline Woods \& Scott, 2016 & $\begin{array}{c}\text { Adolescents }(\mathrm{N}=467) \text { completed a questionnaire } \\
\text { battery either on paper or online. Questionnaires } \\
\text { were related to sleep quality, anxiety, DS, self- } \\
\text { esteem, emotional investment, and nighttime use } \\
\text { of SM. }\end{array}$ & $\begin{array}{l}\text { Those who used SM more and had higher levels of } \\
\text { emotional investment in SM had poorer sleep } \\
\text { quality, higher anxiety and DS and lower self-esteem } \\
\text { compared to those who used SM less often. }\end{array}$ & Yes \\
\hline
\end{tabular}

\section{Discussion}

The purpose of the present literature review was to investigate the relationship between high SM use and DS rates in adolescents. In general terms, results obtained in this review support my hypothesis, as higher levels of selfreported DS are typically found when adolescents engage in higher use of Facebook.

The results of this study indicate that there may exist mediating and moderating variables which drive the relationship between SM use and DS. For example, Frison and Eggermont (2015) found a difference between the type of Facebook use (active vs. passive) and between the sex of the individual (male vs. female). Specifically, females who engaged in passive Facebook use and males who engaged in active Facebook use reported higher levels of DS. Nesi and Prinstein (2018) also found a sex difference in their study, as females presented a relatively stronger relationship between DS and social feedback and/or comparison. Thus, the sex of an individual and the type of SM use (passive vs. active) may play roles in the relationship between SM use and DS in adolescents. 
The results of this review must be considered with their limitations. This study did not provide a specific operational definition for SM, yet there are many ways in which an individual can use Facebook (e.g., posting, liking, commenting). The current literature review also did not utilize a specific definition of "high SM use." This construct can be defined in many ways (e.g., number of hours spent, number of interactions online, etc.). When examining the literature, narrowing the type of SM use led to an extremely limited number of results being showcased, so an sufficient number of studies were located within this narrow scope. One final limitation of the current literature review is that Facebook was the only type of SM examined. Adolescents engage in many other forms as social media (e.g., Snapchat, Instagram, Tiktok, Twitter). It is possible that there exist significantly different relationships between DS in adolescents and SM platforms.

There is a gap in the literature in regard to the use of SRMs to measure DS in adolescents. Almost all studies in this review utilized SRMs, so there is a possibility of invalidity in DS level reporting. SRMs are subject to response biases, such that individuals may attempt to be more socially desirable (Holtgraves, 2004), leading to inaccurate results and misleading findings. To overcome this, future studies should focus on using behavioural measures such as implicit or ambiguous tasks to measure DS levels instead of solely relying on SRMs, thereby reducing response biases.

Future studies should investigate how different SM platforms (e.g., Snapchat, Instagram, Tiktok, Twitter) and their utilization (e.g., posting, liking, commenting) predict DS in adolescents based on behavioural measures. Mediating and moderating variables should also be examined, including age, sex, education type and length, and cultural. Future studies should also determine the efficacy of IPT in alleviating symptoms of depression in individuals engaging in high SM use.

\section{Note}

This paper was written for a course based in the University of Toronto Scarborough. 


\section{References:}

Blos, P. (1967). The second individuation process of adolescence. Psychoanalytic Study of the Child, 22, $162-186$. https://doi.org/10.1080/00797308.1967.11822595

Dhir, A., Yossatorn, Y., Kaur, P., \& Chen, S. (2018). Online social media fatigue and psychological wellbeing-A study of compulsive use, fear of missing out, fatigue, anxiety and depression. International Journal of Information Management, 40(2018) 141-152. https://doi.org/10.1016/j.ijinfomgt.2018.01.012

Frison, E. \& Eggermont, S. (2015). Exploring the relationships between different types of Facebook use, perceived online social support, and adolescents' depressed mood. Social Science Computer Review, 34(2), 153-171. https://doi.org/10.1177/0894439314567449

Holtgraves, T. (2004) Social desirability and self-reports: testing models of socially desirable responding. The Society for Personality and Socially Psychology, Inc, 30(2), 161-172. https://doi.org/10.1177\%2F0146167203259930

Kross, E., Verduyn, P., Demiralp, E., Park, J., Lee, D. S., Linj, N., Shablack, H, Jonides, J., \& Ybarra, O. (2013). Facebook use predicts declines in subjective well-being in young adults. PloS One, 8(8), e69841. http://doi.org/10.1371/journal.pone.0069841

Koutamanis, M., Vossen, H. G. M., Peter, J., \& Valkenburg, P. M. (2013). Practice makes perfect: The longitudinal effect of adolescents' instant messaging on their ability to initiate offline friendships. Computers in Human Behavior, 2265-2272. http://dx.doi.org/10.1016/j.chb.2013.04.033

Lemola, S., Perkinson-Gloor, N., Brand, S., Dewald-Kaufmann, J.F., \& Grob, A. (2015). Adolescents' electronic media use at night, sleep disturbance, and depressive symptoms in the smartphone age. Journal of Youth and Adolescence, 44, 405-418. https://doi.org/10.1007/s10964-014-0176-x

Lenhart, A. (2015). Teens, social media, \& technology overview 2015. Pew Research Center, Internet and Technology. https://www.pewresearch.org/internet/2015/04/09/teens-socialmedia-technology-2015/

Muzaffar, N., Brito, E.B., Fogel, J., Fagan, D., Kumar, K., \& Verma R. (2018). The association of adolescent Facebook behaviours with symptoms of social anxiety, generalized anxiety, and depression. Journal of the Canadian Academy of Child and Adolescent Psychiatry, 27(4), $253-$ 260. https://www.cacap-acpea.org/learn/journal/ 
Nesi, J. \& Prinstein, M.J. (2018). Using social media for social comparison and feedbackseeking: gender and popularity moderate associations with depressive symptoms. Journal of Abnormal Child Psychology, 43(8), 1427-1438. https://doi.org/10.1007/s10802-015-0020-0

Obar, J. A., \& Wildman, S. S. (2015). Social media definition and the governance challenge: An introduction to the special issue. Telecommunications Policy, 39(9), $745-750$. http://dx.doi.org/10.2139/ssrn.2647377

O'Keeffe, G., Clarke-Pearson, K. \& Council on Communications and Media (2011). The impact of social media on children, adolescents and families. Pediatrics, 124, 800-804. https://doi.org/10.1542/peds.2011-0054

Ophir, Y., Asterhan, C.S.C., \& Schwarz, B.B. (2019). The digital footprints of adolescent depression, social rejection and victimization of bullying on Facebook. Computers in Human Behavior, 91(2019) 62-71. https://doi.org/10.1016/j.chb.2018.09.025

Swartz, H.A., \& Novick, D.M. (2020). Psychotherapy in the digital age: what we can learn from interpersonal psychotherapy. The American Journal of Psychotherapy, 73(1), 15-21. https://doi.org/10.1176/appi.psychotherapy.20190040

Vannucci, A. \& Ohannessian, C.M. (2019). Social media use subgroups differentially predict psychosocial well-being during early adolescence. Journal of Youth and Adolescence, 48, 14691493. https://doi.org/10.1007/s10964-019-01060-9

Woods, H. C. and Scott, H. (2016) \#Sleepyteens: social media use in adolescence is associated with poor sleep quality, anxiety, depression and low self-esteem. Journal of Adolescence, 51, 41 -49. https://doi.org/10.1016/j.adolescence.2016.05.008 